\title{
COMO ENSINAR O USO CORRETO DO DIAFRAGMA EM EXERCÍCIOS RESPIRATÓRIOS
}

ARAÚJO, C.P. - Como ensinar o uso correto do diafragma em exercícios respiratórios. Rev. Esc. Enf. USP, 7(2): 140-143, 1973.

Pacientes podem não saber usar corretamente seu diafragma em exercicios respiratórios. $O$ enfermeiro pode ajudá-los colocando suas mãos com pequena pressão sobre a regiäo infra-mamária e infra-axilar do paciente durante a inspiração, e este na expiração deverá contrair sua musculatura abdominal. Isto facilitará a aprendizagem da respiraçāo torácico-diafragmática enquanto o paciente adquire também, nesse processo, a percepção do movimento do diafragma.

A importância de exercícios respiratórios no pré-operatório para melhor expansão pulmonar, prevenindo algumas complicações no pósoperatório, tanto em cirurgias torácicas quanto abdominais, já é bastante conhecida. Estudos feitos com quatro diferentes tipos de exercícios nos são relatados por Collart (1971) quando pesquisou qual dos tipos seria o mais eficiente para prevenir atelectasias pós-cirúrgicas e concluiu que para cada indivíduo há um determinado tipo de exercício que é mais produtivo.

Seja qual for o tipo empregado, o papel do pessual de enfermagem é o de ensinar o paciente a respirar corretamente para que os exercícios alcancem os seguintes objetivos: máxima expansão pulmonar possível, para a boa oxigenação, e melhor desprendimento da mucosidade que será expelida da árvore brônquica com o processo da tosse.

Para tanto, torna-se mister conhecer a fisiologia da respiração

- Auxiliar de Ensino da disciplina Enfermagem Cirürgica. 
a fim de que o enfermeiro, assistindo ao paciente, possa explicar-lhe em poucas e simples palavras, a importância dos exercícios, bem como ser capaz de ajudá-lo na prática.

Três tipos de respiração são conhecidas: respiração abdominal ou diafragmática, respiração torácica e a combinação das duas que é a mais eficiente por constituir a que abrange maior capacidade pulmonar. $\mathrm{Na}$ maioria das vezes, o enfermeiro é compelido a pedir ao paciente sua colaboração, a fim de que respire profundamente durante os exercícios, sem esquecer que nem sempre o paciente sabe fazer uso combinado da respiração abdominal e torácica. Cabe ao pessoal do serviço de enfermagem esta responsabilidade em dedicar alguns minutos ao paciente ensinando-lhe a respiração combinada.

Propomo-nos aqui a dar pequena explicação de como o pessoal de enfermagem pode auxiliar o paciente na prática de exercícios, uma vez que o mesmo já tenha conhecimento da sua importância e necessidade.

Colocando-se o paciente em posição semi-sentada, confortável. com joelhos pouco flexionados para facilitar pleno relaxamento do diafragma, pedimos ao mesmo que concentre sua atenção na inspiração e inspire profundamente três vezes. Isso permitirá que ele sinta a diferença da respiração quando usa o diafragma adequadamente.

A seguir o enfermeiro, colocando sua mão sobre a musculatura abdominal do enfermo, pede-lhe que a contraia o mais que puder, com a boca fechada. Chegou a hora da inspiração que é feita pelo conduto nasal, tentando o paciente empurrar com os músculos abdominais a mão do orientador. ( $\mathrm{O}$ diafragma apresenta-se relaxado, ou seja em posiçāo descendente). 0 ar, no ato da expiração, deve ser expelido pela boca, lentamente, enquanto os músculos abdominais novamente se contraem. Repete-se o exercício cinco vezes.

Após pequenv repouso, o enfermeiro colocará suas duas mãos em cima da área onde estão situadas as 7 ạ, 8 a e 9 ạ costelas exercendo pequena pressão. Pede-se ao paciente que inspire pelas narinas tentando aumentar a caixa torácica e empurrando as mãos do orientador. A expiração se fará também pela boca. expelindo-se o ar lentamente e fazendo com que a caixa 
torficica diminua, sofrendo a pequena pressão imposta pelas mãos do enfermeiro. Repete-se o exercício cinco vezes.

Novamente um pequeno descanso e, desta vez, com as mãos do paciente sobre seu próprio abdomen, $e$ as mãos do enfermeiro abrangendo a região infra-mamária e a infra-axilar direita e esquerda, o doente deverá tentar a respiração diafragmática e a torácica combinadas. Na expiração terá os músculos abdominais contraídos e o volume da caixa torácica diminuída. Na inspiração, tentará empurrar suas mãos com os músculos abdominais e expandir a caixa torácica forçando as mãos do orientador.

Em todo este processo, devemos lembrar que, inicialmente o exercício não deve ser repetido mais do que cinco a seis vezes em virtude do paciente geralmente apresentar tonturas causadas pela depleção do dióxido de carbono, no ato da inspiração profunda.

Para se obter bom resultado na respiração correta, esses exerćcios devem ser feitos várias vezes por dia a fim de que o paciente fique acostumado a usar o diafragma em toda sua extensão quando solicitado a fazer exercicios respiratórios, quer seja com os frascos, quer com aparelhos de respiraçăo ou por outro método qualquer. A eficácia para se obter em resultados nos objetivos traçados depende da clareza na explanação e da perceveranga na prática dos exercícios ensinados. Isto feito, a enfermagem terá certeza de que estará dando sua contribuição junto à equipe de saúde para o bem estar do paciente.

ARAOJO, C.P. - Teaching patients how to use the diaphragm correctly in breathing exercices. Rev. Esc. Enf. USP, 7(2): 140-143,1973.

Patients sometimes don't know how to use: their diaphragm correctly in breathing exercices. The nurse may help by placing her hands around the rib cage while the patient's hands press his abdomen; this care facilitates the learning of the diaphragm's movement and makes it easier for the patient to inhale, using together the thorax and the diaphragm for greater lung expansion. 


\section{REFERENCIAS BIBLIOGRÁFICAS}

ANTHONY, C.P. - Textbook of anatomy and physiology. 6th ed. Saint Louis, Mosby, 1963.

COLLART, M.E. - Preventing postoperative atelectasis. Amer. J. Nurs. 71 : 1982-7, Oct. 1971.

ELLIS, C.R. - Fundamental breathing exercices. Nurs. Mirror, 130:34-5, Feb. 1970.

HEALY, K.M. - Does preoperative instruction make a difference? Amer. J. Nurs., 68 (1):62-7, Jan. 1968. 